\title{
Differences in the tensile strength of direct nanohybrid composite veneers between the V and VIII generation dentin bonding agent after extracoronal bleaching
}

\author{
Erlin Zuke Rizkia*, Setiadi Warata Logamarta*, Irfan Dwiandhono** \\ *Department of Orthodontics Faculty of Dentistry Jenderal Soedirman University, Indonesia \\ ${ }^{* *}$ Department of Conservative Dentistry Faculty of Dentistry Jenderal Soedirman University, \\ Indonesia
}

\begin{abstract}
Introduction: Tooth discolouration is the most common esthetic problems in dentistry. Direct composite veneer is an adjunctive therapy for severe teeth discolouration by attaching to the tooth surface using an acid etching and dental bonding agent. In several cases of severe discolouration, it is required to have certain preliminary treatments such as bleaching prior to the placement of the composite veneer. However, bleaching agents are able to lead the enamels morphology and microstructure alteration by inhibiting the polymerisation bonding thus affecting the veneer adhesion. This study was aimed to determine the tensile bond strength of direct composite veneers between the $\mathrm{V}$ and VII generation dentin bonding agent after extracoronal bleaching. Methods: This study was an experimental laboratory of as much as 32 human permanent maxillary central incisors were divided into 4 groups. Group 1 was treated with extracoronal bleaching and bonded with the $\mathrm{V}$ generation bonding nanohybrid composite. Group 2 was treated with extracoronal bleaching and bonded with the VIII generation bonding nanohybrid composite. Group 3 was only bonded with the $\mathrm{V}$ generation bonding nanohybrid composite. Group 4 was only bonded with the VIII generation bonding nanohybrid composite. All samples were immersed in artificial saliva then incubated at the room temperature for 24 hours. Results: The tensile strength value was determined using the Universal Testing Machine. The ANOVA test results showed significant differences in all four groups $(\mathrm{p}<0.05)$. Conclusion: The VIII generation bonding agent had a higher tensile strength than the $\mathrm{V}$ generation.
\end{abstract}

Keywords: bleaching, direct veneer composite, tensile strength, $V$ generation bonding, VIII generation bonding, tensile bond strength

p-ISSN 1979-0201, e-ISSN 2549-6212 Available from: http://jurnal.unpad.ac.id/pjd/article/view/16112

DOI: http://dx.doi.org/10.24198/pjd.vol30no1.16112

Submission: Dec 2017 Publishing: Mar 2018

Corresponding author: Erlin Zuke Rizkia, Department of Orthodontics Faculty of Dentistry Jenderal Soedirman University Dr. Soeparno St., Karawangkal Campus Building E, Banyumas, Central Java 53122. e-mail: erlinzuke@gmail.com 


\section{INTRODUCTION}

Anterior teeth play an important role in the aesthetical part because they can affect the appearance, improve self-confidence and quality of life. Tooth discolouration is a very disturbing aesthetic problem for certain patients. ${ }^{1}$ Tooth discolouration can be caused by extrinsic or intrinsic factors. Extrinsic discolouration is caused by pigmented organic molecules (chromogen) from food, beverages, mouthwash, and cigars. Intrinsic discolouration is a colouration caused by structural changes in the tooth hard tissue. ${ }^{2}$ Severe intrinsic discolouration such as fluorosis, tetracycline, devitalization, and ageing are discolouration often treated with composite veneers. ${ }^{3}$

The veneer is a thin layer and made of dental restorative materials. Based on how the veneer is divided into two types: direct (direct) and indirect (direct). Direct veneer is a veneer made directly in the oral cavity. ${ }^{4}$ One of the direct veneer materials that can be used is the nanohybrid composite because it contains nanosized filler particles $(\leq 100 \mathrm{~nm})$ and micro $(0.1-2$ $\mu \mathrm{m})$ which produces a mechanical strength well, as well as having finishing and polishing results almost resembling porcelain restorations..$^{5,6}$ Direct composite veneers are attached to the tooth surface using acid etching and dental bonding agent.

One of the commonly used bonding materials today is the $\mathrm{V}$ generation that uses the total etch application technique. The bonding of generation $\mathrm{V}$ with the tooth is obtained by the mechanical interlocking mechanism through the formation of tag resin, adhesive material linkage, and hybrid layer formation. The combined primary and adhesive content comprise hydrophobic and hydrophilic bifunctional monomers. The combination allows for good bonding of both email and dentin. ${ }^{7}$

The bonding material continues to developed with the aim of gaining strength better than the previous generation. The development of bonding material has now reached the generation VIII that can be applied with total-etch or self-etch technique. The bonding attachment of generation VIII is obtained through a combination of mechanical and chemical bonds. The preparation of a class VIII bonding material comprises a combined etching, primer, and adhesive liquid reinforced by a silicon dioxide (SiO2) nanofillers component. Nanofillers produce thicker and more flexible hybrid layers that can increase attachment strength. ${ }^{8}$ This bonding bond strength is also supported by the content of 10-methacryloyloxydecyl dihydrogen phosphate (MDP) and methacrylate carboxylic acid polymer (MCAP) which will form chemical bonds with tooth hydroxyapatite. ${ }^{9}$

Some cases of heavy discolouration sometimes require preliminary treatment in the form of bleaching before restorative procedures, aimed at obtaining a dental base colour to increase esthetic value. ${ }^{10}$ One bleaching technique that can be used is extracoronal bleaching, but the application of bleaching materials can lead to morphological and microstructural changes in email caused by the presence of organic molecular bonds and the oxygen residue that hydrogen peroxide released in the enamel structure. The oxygen residue can inhibit polymerisation and increase the porosity of the bonding material, thus affecting the strength of veneer adhesion on the teeth applied after bleaching $1 .^{11}$

The direct composite restoration of postbleaching teeth has the lowest survival rate of 2-7 years, compared with veneer and crown restoration of 10-12 years. ${ }^{12}$ Therefore, researchers wanted to prove the effect of bleaching on the tensile strength of composite direct veneers in vitro and examined the difference in tensile strength of composite direct veneer composites between $\mathrm{V}-\mathrm{V}$ and VIII post-bleaching extracoronal. The researchers chose to use the tensile strength test in this study because the load is applied on both sides of the test object perpendicularly to the axis so that the force distribution on the entire surface is more homogeneous than the shear strength test. ${ }^{13}$

\section{METHODS}

The type of research conducted in this study was laboratory experimental with the post test only control group design. This study used a sample of 32 permanent maxillary incisors. Tooth samples were cleaned and cut $1 \mathrm{~mm}$ above the Cemento Enamel Junction (CEJ) using diamond cutting edge bur, then dental crown planted in acrylic self cure with 
labial section upwards, then divided into 4 groups at random, which were group 1, extracoronal bleaching and nanohybrid composite direct veneer application using bonding generation V; Group 2, extracoronal bleaching and nanohibrid composite direct veneer applications using generation VIII; Group 3: nanohybrid composite direct veneer using bonding generation V; Group 4, nanohybrid composite direct veneer using bonding generation VIII.

The bleaching group treated sample was applied $40 \%$ hydrogen peroxide gel for 20 minutes according to the manufacturer's instructions, then cleaned with suction. After the bleaching

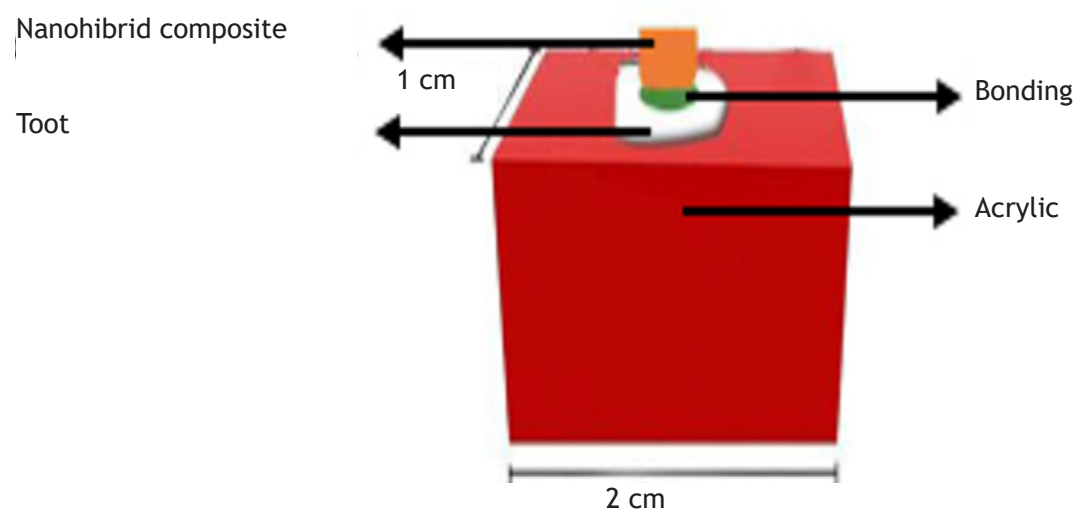

Figure 1. Research sample

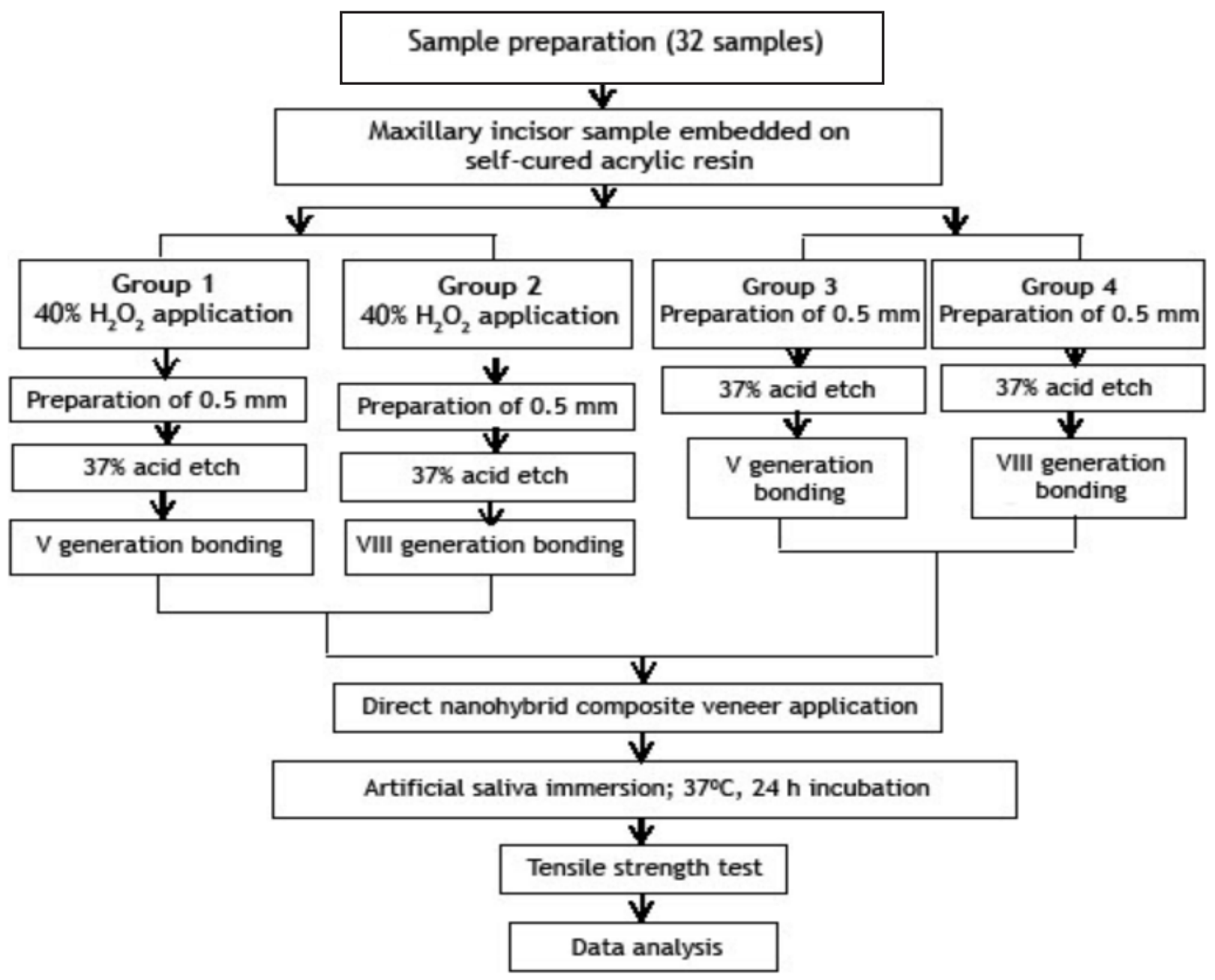

Figure 2. Research procedure scheme 
procedure was completed the topical fluorine is then rinsed with water.

All tooth samples were prepared by 0.5 $\mathrm{mm}$ of preparation on the labial surface using depth-cutting bur, then etching of enamel was then rinsed and dried by air spray slowly. Groups 1 and 3 then applied bonding generation $\mathrm{V}$ using a micro brush, let stand 10 seconds according to the manufacturer's instructions, then light cured for 10 seconds. The generation VIII bonding was applied to group 2 and 4 by scrubbing using a 20 -second micro brush according to the manufacturer's instructions, then light cured for 10 seconds.

After the bonding treatment, the nanohybrid composite attachment was applied to all tooth samples using acrylic prints of $5 \times 5 \times 3 \mathrm{~mm}$ size. The mould was placed on the labial surface, the composite is inserted into the mould to the full using a plastic filling instrument, then lighted with a light cure for 20 seconds. All samples were immersed in artificial saliva and incubated at $37^{\circ} \mathrm{C}$ for 24 hours. A total of 32 dental samples were tested for tensile strength using Universal
Testing Machine. The data obtained were then tested for normality using Shapiro-Wilk test and homogeneity test using Levene test. Normally distributed and homogeneous data, followed by parametric analysis using one-way ANOVA and continued Post Hoc LSD test.

\section{RESULTS}

Data of tensile strength of direct nanohybrid composite veneer after calculated using the formula can be seen in Figure 3.

Figure 3 showed that the highest tensile strength value was found in Group 4 with the value of $12.29 \pm 2.34 \mathrm{MPa}$, whilst the lowest value was found in Group 1 with the value of $5.94 \pm 1.77 \mathrm{MPa}$. The data of tensile strength was then tested for normality using Shapiro-Wilk and homogeneity test using Levene test. The normality and homogeneity test results showed that the data were normally distributed and the whole homogeneous group data $(p>0.05)$, then can be done using one-way ANOVA test. Interaction test results between the

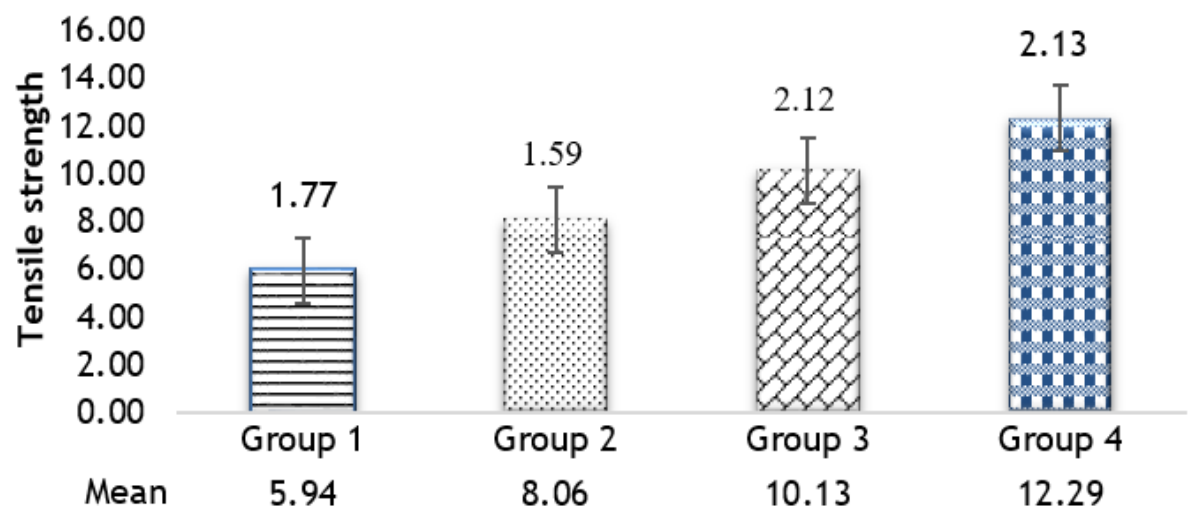

日Group 1 Group 2 घGroup 3 Group 4

Figure 3. Tensile strength of direct nanohybrid composite veneer (MPa)

Table 1. LSD test result of the tensile strength between all groups

\begin{tabular}{cccccc}
\hline No & Sample & Group 1 & Group 2 & Group 3 & Group 4 \\
\hline 1 & Group 1 & & $-2.12125^{*}(\mathrm{p}=0.035)$ & $-4.19250^{*}(\mathrm{p}=0.000)$ & $-6.34875^{*}(\mathrm{p}=0.000)$ \\
2 & Group 2 & $-2.12125^{*}(\mathrm{p}=0.035)$ & & $-2.07125^{*}(\mathrm{p}=0.040)$ & $-4.22750^{*}(\mathrm{p}=0.000)$ \\
3 & Group 3 & $-4.19250^{*}(\mathrm{p}=0.000)$ & $-2.07125^{*}(\mathrm{p}=0.040)$ & & $-2.15625^{*}(\mathrm{p}=0.033)$ \\
4 & Group 4 & $-6.34875^{*}(\mathrm{p}=0.000)$ & $-4.22750^{*}(\mathrm{p}=0.000)$ & $-2.15625^{*}(\mathrm{p}=0.033)$ & \\
\hline \multicolumn{7}{c}{ Notes: $^{*}=$ significant difference $(\mathrm{p}<0.05)$}
\end{tabular}


groups showed a significant difference $(p<0.05)$. LSD Post Hoc follow-up tests were conducted to determine the significant differences between each treatment group presented in Table 1.

Statistical test results using LSD showed that all groups had statistically significant differences with significance values $(p<0.05)$.

\section{DISCUSSION}

The value of tensile strength of direct nanohybrid composite veneer post-bleaching extracoronal was lower than that of a group without bleaching. The decrease of tensile strength of direct composite veneer tensile on post-bleaching occurred due to morphological and microstructural changes on the surface of the enamel caused by bleaching material applications. One of the best methods for studying enamel surface is SEM. Post-bleaching enamel surface observation results by Miranda in 2005 showed that the surface morphology changed after bleaching applications include aprismatic layer loss, increased depth of enamel flow, and exposure to enamel prism. Such changes may cause leaks and fracture on restoration. ${ }^{14}$

Hydrogen peroxide is a powerful oxidiser that will not only break down chromogenic molecules, but it can also alter the inorganic composition of the tooth by increasing mineral solubility because of the low $\mathrm{pH}$ of the bleaching material. The loss of dental minerals such as calcium and phosphate causes morphological changes on the surface of the enamel including crater formation, porosity enhancement, enamel erosion, and partial dissolution of enamel prisms. ${ }^{14}$

The chemical microstructural changes on the enamel surface are related to the presence of oxygen residues from the degradation of hydrogen peroxide. The oxygen residue will be trapped in the bonding resin during the light cure process which can inhibit the polymerisation process of the bonding material by breaking the elongation of the polymer chains resulting in premature termination of the polymer chain. ${ }^{15}$ This condition may cause damage to mechanical retention that affects the bonding reduction. Another factor that can affect the value of tensile strength in this study was the use of the totaletch technique by applying phosphoric acid.

The normal acid etching application in normal enamel dissolves some of the tooth minerals, thus removing about $10 \mu \mathrm{m}$ of enamel surface and forming a microporosity with a consistent pattern as deep as 5-50 $\mu \mathrm{m} .{ }^{16}$ The microporosity serves as the mechanical retention of the bonding material to form mechanical interlocking. The enamel surface post-bleaching has been demineralised, and morphological changes occur, so the acid etching application in the post-bleaching tooth can cause excess demineralisation. The postbleaching acid etching application can cause over-etched enamels with loss of enamel prism boundaries and increase enamel porosity. ${ }^{17}$ This condition may affect the quality of bonding retention and composite resins in enamels.

The results of this study showed that composite direct veneer in post-bleaching enamels using VIII generation bonding (Group 2) had a higher tensile strength compared to groups using $\mathrm{V}$ generation bonding (Group 1). This condition can happen because both types of bonding generation are used to obtain bonding attachment to the tooth in different ways. The bonding attachment of the $\mathrm{V}$ generation is obtained mechanically by the mechanical interlocking mechanism by the formation of tag resin, adhesive branching, and hybrid layer formation, while the bonding attachment of generation VIII was obtained through a combination of mechanical and chemical bonds.

The result of the tensile strength test shows that the use of the bonding type significantly affects the tensile strength of nanohybrid composite direct veneers in post-bleaching enamels as shown in Table 1. Bonding generations $\mathrm{V}$ and VIII obtain mechanical bonds through penetration of the bonding material on the microporosity of enamel generated by $37 \%$ phosphoric acid etching application, while in the generation VIII bonding group in addition to obtaining mechanical bonds also obtained chemical bonds through the presence of methacrylate carboxylic acid polymer (MCAP) and methacryloyloxydecyl dihydrogen phosphate (MDP). This condition allowed bonding of generation $\mathrm{V}$ to have a lower tensile strength compared to generation VIII. MCAP is a functional carboxylic acid polymer which produces bonding by forming a chain group of carboxylic acid polymers which can react and bind hydroxyapatite to produce multiple bonds on tooth surfaces. Also, the MDP 
content of the generation VIII bonds will result in a non-soluble precipitate of calcium $\left(\mathrm{Ca}^{2+}\right)$ salts. Calcium salts produced by MDP have a high affinity that will form a chemical bond with calcium on tooth hydroxyapatite and forming nano-layering. ${ }^{18}$ This result allows for good bonding between generation VIII and dental bonding materials. The mechanical retention disorder caused by the presence of oxygen residue from the bleaching material can be supported by the chemical bonds of the components contained in the generation VIII bonds to produce higher tensile strength.

The type of bonding material used may affect the tensile strength and adhesion of emails that have been given bleaching applications. ${ }^{19}$ Previous studies by Joseph in 2013 and Kable et al. in 2015 reported that generation VIII showed the highest tensile strength. The study compared the VI, VII, and VIII bonding materials on the teeth without bleaching application, 20,21 whereas this study compared the $\mathrm{V}$ and VIII generation post extracoronal bleaching.

\section{CONCLUSION}

The VIII generation bonding agent had a higher tensile strength than the $\mathrm{V}$ generation on the use after extracoronal bleaching.

\section{REFERENCES}

1. Bittencourt ME, Trentin MS, Linden MS, Lima-Arsati YBDO, Franca FM, Florio FM et al. Influence of in situ postbleaching times on shear bond strength of resin-based composite restorations. J Am Dent Assoc 2010 Mar;141(3):300-6.

2. Ingle JI, Bakland LK, Baumgartner JC. Ingle's endodontics $6.6^{\text {th }}$ ed. Ontario: BC Decker, Inc; 2008. p. 1383.

3. Goldstein RE, Chu S, Lee E, Stappert CFJ, Esthetics in dentistry. $3^{\text {rd }}$ ed. Ontario: $B C$ Decker, Inc; 2018. p. 342.

4. Garg N, Garg A. Textbook of operative dentistry. $3^{\text {rd }}$ ed. New Delhi: Jaypee Brothers Medical Publishers; 2015. p. 309.

5. Anusavice KJ. Phillip's science of dental material. 12st ed. St. Louis: Saunders-Elsevier; 2013. p. $169,262,265,279-81$.

6. Halley E. Direct composite veneers-An aesthetic alternative. Privat Dent 2012 Feb;2012:1-4.

7. Huang $X$, Li L, Huang $C$, Du X. Effect of ethanolwet bonding with hydrophobic adhesive on caries-affected dentine. Eur J Oral Sci 2011 Aug;119(4):310-5. DOI: 10.1111/j.16000722.2011.00830.x.

8. Hatrick CD, Eakle WS. Dental materials clinical applications for dental assistants and dental hygienists $3^{\text {rd }}$ ed. St. Louis: Elsevier; 2016. p. 53.

9. Farias DCS, De Andrada MAC, Boushell LW, Walter R. Assessment of the initial and aged dentin bond strength of universal adhesive. Int J Adhes Adhes 2016 Oct;70:53-61. DOI: 10.1016/j.ijadhadh.2016.05.008.

10. Freedman GA. Contemporary Esthethic Dentistry. St. Louis: Mosby-Elsevier; 2012. p. 343.

11. Shinohara MS, Peris AR, Rodrigues JA, Pimenta LA, Ambrosano GM. The effect of nonvital bleaching on the shear bond strength of composite resin using three adhesive systems. J Adhes Dent 2004 Autumn;6(3):205-9.

12. Clark S. Optimum life-time management of coronal fractures in anterior teeth: A review of crowns, veneers, composites resins restorations and intra-coronal bleaching. Eviden Based Brief Rep 2008 Jul;2008:1-105.

13. Sakaguchi RL, Powers JM. Craig's Restorative Dental Materials. 13th ed. St. Louis: MosbyElsevier; 2013. p. 86,97,163-9,329.

14. Miranda CB, Pagani C, Benetti AR, Matuda FDS. Evaluation of the bleached human enamel by scanning electron microscopy. J Appl Oral Sci 2005 Apr/Jun;13(2):204-11.

15. Lima AF, Sasaki RT, Araujo LS, Gaglianone LA, Freitas MS, Aguiar FH et al. Effect of tooth bleaching on bond strength of enameldentin cavities restored with silorane and dimethacrylate-based materials. Oper Dent 2011 Jul-Aug;36(4):390-6. DOI: 10.2341/10332-L

16. Dhingra A, Singh A. Its all about bonding. J Dent Sci Oral Rehab 2014;5(4):213-9.

17. Montalvan E, Vaidyanathan TK, Shey Z, Janal MN, Caceda JH. The shear bond strength of acetone and ethanol-based bonding agents to bleached teeth. Pediatr Dent 2006 NovDec;28(6):531-6. 
18. Trindade TF, Moura LK, Neto RW, Messias DC, Colucci V. Bonding effectiveness of universal adhesive to intracoronal bleached dentin treated with sodium ascorbate. Braz Dent J. 2016 May-Jun;27(3):303-8. DOI: 10.1590/01036440201600647

19. El-Seoud HKA, Ibrahim MA, Hafez R. Proper timing of bonding composite resin to bleached enamel. Cairo Dent J. 2008 Sep;24(3):437-46.

20. Paul J, Chakravarthy Y, Kumar S, Rahna
R. Comparative evaluation of the bonding efficacy of sixth, seventh, and eighth generation bonding agents: An in vitro study. Int Res J Pharm. 2013 Oct;2(9):143-7.

21. Kamble SS, Kandasamy B, Thillaigovindan R, Goyal NK, Talukdar P, Seal M. In vitro comparative evaluation of tensile bond strength of 6th, 7th, and 8th generation dentin bonding agents. J Int Oral Health. 2015 May; 7(5):41-3. 